This item was submitted to Loughborough's Research Repository by the author.

Items in Figshare are protected by copyright, with all rights reserved, unless otherwise indicated.

\title{
'Tuning out' or 'tuning in'? mobile music listening and intensified encounters with the city
}

PLEASE CITE THE PUBLISHED VERSION

http://dx.doi.org/10.1111/1468-2427.12443

\section{PUBLISHER}

(c) Urban Research Publications Ltd. Published by John Wiley \& Sons

VERSION

AM (Accepted Manuscript)

\section{PUBLISHER STATEMENT}

This work is made available according to the conditions of the Creative Commons Attribution-NonCommercialNoDerivatives 4.0 International (CC BY-NC-ND 4.0) licence. Full details of this licence are available at: https://creativecommons.org/licenses/by-nc-nd/4.0/

\section{LICENCE}

CC BY-NC-ND 4.0

\section{REPOSITORY RECORD}

Watson, Allan, and Dominiqua Drakeford-Allen. 2019. "'tuning Out' or 'tuning In'? Mobile Music Listening and Intensified Encounters with the City". figshare. https://hdl.handle.net/2134/22718. 


\title{
'Tuning out' or 'tuning in'? Mobile music listening and intensified encounters with the city
}

\begin{abstract}
Mobile music listening has become an increasingly pervasive part of urban life. Yet it represents an area of enquiry with which urban studies scholars have yet to meaningfully engage. This paper considers the role of mobile music devices in creating new sonic, emotional and social interactions with and within the city. While academic work in this area has emphasized the use of these devices as a 'tuning out' of the physicality of the city, we suggest that they might also be used as part of a 'tuning in' that enhances the meaning and intensity of engagements with the city. In making this case, the paper considers two areas of academic enquiry that highlight the use of mobile music devices in intensified engagements with the city: first, recent writing on the sonic ecologies of the city that emphasize 'city sounds' as part of the urban experience; and second recent advances in the field of urban computing that provide technologies for location-aware music-exchanges and mediated social interactions. The paper emphasizes mobile music listening as one area of critical enquiry that can help develop our understanding of the ways in which the pervasiveness of mobile devices is recalibrating the experience of urban spatiality.
\end{abstract}




\section{Introduction}

In recent years, spurred by the development of the MP3 software format and mobile music devices such as Apple’s iPod and iPhone, listening to music 'on the move' has become an increasingly pervasive part of city life. Research undertaken by Universal Music in late 2012 (Smernicki, 2013) suggested that mobile devices - phones, tablets, and MP3 players are now the adult populations most preferred way of listening to music, ahead of radio, in-car listening and hi-fi. Indeed, these devices have become so significant in everyday life, so embedded and intimately incorporated into routine bodily practices (Beer, 2012), that to understand personal engagements with the city, one cannot ignore their impact. Developing concomitantly with these devices, the increased prevalence of Wi-Fi and high speed mobile data networks such as 4G is creating a new kind of 'electromagnetic space' (Fuller and Harley, 2011) within the urban environment. As listeners move through the city, they are able to tap into these networks and call upon a musical soundtrack that allows them to create their own personal, experiential geographies of the city. Not only do such technologies allow for listening to music on the move, but they also allow the recall of music on-demand from large libraries saved on these devices or increasingly from on-demand music streaming sites. Thus these devices allow listeners to create customized personal 'soundtracks' to their day-to-day lives, on-demand and as their mood and emotions suit. These technologies thus draw our attention to the changing relationships between bodies and space.

Given the increased interest amongst geographers and urban scholars in sonic geographies and urban sounds and soundscapes (see amongst others Arkette, 2004; Atkinson, 2007; Gallagher and Prior, 2013; Belgiojoso, 2014; and Wissman 2014), as part of a wider 
consideration of what has become termed 'sensory urbanism', it seems to us surprising that mobile music listening is an area of study with which urban studies scholars have yet to meaningfully engage. In this article, we consider the role of mobile music devices in creating new sonic, emotional and social interactions with and within the urban environment. While academic work in this area has emphasized the use of these devices as a 'tuning out', to various degrees, of the physical in favor of the virtual (Bull, 2005, 2007, 2013), in this article we argue that this only offers a partial account of the plurality of strategies that listeners use to manage their environments (Prior, 2014). Specifically, we point to the ways in which listeners might also use music as part of a 'tuning in’ to the urban environment that enhances the meaning and intensity of engagements with the city and others within it. In making this case, we highlight two areas of academic enquiry that highlight the use of mobile music devices in intensified engagements with the city: first, recent writing on the sonic ecologies of the city that emphasize 'city sounds' as part of the urban experience; and second, recent advances in the field of urban computing that provide technologies for location-aware situated music-exchanges and shared music interactions between mobile music listeners. We seek to emphasize the importance of engaging with this area of study as one which can aid us in better understanding the ways in which pervasive mobile devices are recalibrating individual and collective experience of urban spatiality, through the creation of 'ubiquitous body-network relations' (Fuller and Harley, 2011).

\section{Tuning out: mobile music devices and isolated practices of listening}

The term 'mobile music device' refers to a range of different portable, light-weight music storage and playback devices. Two different 'iconic' devices have come to represent the analogue and digital ages respectively: the Sony Walkman portable cassette player, and 
Apple’s iPod. Launched in October 2001, the iPod revolutionized mobile music listening by providing a large amount of digital storage capable of storing thousands of songs, allowing listeners for the first time to carry their entire music library with them. Subsequently, Apple’s iPhone range would come to have the same media player capabilities as the iPod line of products, and in 2010 sales of the iPhone overtook those of the iPod. The move to mobile phones as the primary device for mobile music listening has proven to be a significant one; the ability of these devices to access the internet on the move, via mobile data and $\mathrm{Wi}-\mathrm{Fi}$ networks, lead to the development of web services and apps (for example, Spotify and more recently Apple Music) that not only allow users to download music, but also to stream music directly to their phone on-demand. This allows listeners a high level of control and management over their music choices and selections. As such, these devices have fundamentally transformed practices of music collection, reproduction and retrieval (Beer, 2008).

For Michael Bull - the first academic to undertake a serious academic appraisal of the impact of mobile music devices - such devices provide an "intoxicating mixture of music, proximity and privacy whilst on the move” (2005; 344). The combined elements of private music and space, and the ability to adjust emotions through music, he argues, creates an individual corporeal experience of urban space that can change, and be changed, almost immediately. The focus of Bull's work has been in particular how detailed elements of the surroundings can be disregarded in place of desired alternative elements for the listener. For Bull, iPod users “make the urban street conform to their own aesthetic desire” (Bull, 2005; 350) and as such urban surroundings can be transformed to suit the mood or thoughts of the listener, and can be interpreted how the listener wishes; that is to say that it offers a means for aesthetic, cognitive and social ordering and control (Bull, 2007; Simun 2009). Users of these 
devices, he suggests, may be aware of an emotion or their mood, and they may strategically plan to enhance or change that mood, often in order to make as a way of dealing with common stressors of everyday urban life such as crowding and noise (Skånland, 2011). This is perhaps best demonstrated through the use of playlists, which can be pre-organized on music storage devices or on streaming sites and mobile phone apps with particular moods and journeys in mind. One might think of these playlists as a form of planned 'soundtrack' to the urban environment. Interpreted in this way, the urban environment becomes a backdrop to a personally-constructed narrative based around the user's emotions and imaginations, in which strangers are extras and the soundtrack delivered through earphones (see Bull, 2013).

In this sense, mobile music listening can be seen as decomposing the territorial structure of the city and recomposing it through 'spatio-phonic behaviors' (Thibaud, 2003). The material world becomes a quasi-cinematic image to the mobile soundtrack (Biggs, 2008), with the world being drawn into the user's individual narrative, rather than the street drawing the user into its realm (Bull, 2013). For Bull, "iPods are by their very nature primarily a privatizing technology” $(2007,5)$ that enable the creation of solitude-inducing, privatized and pleasurable auditory 'bubbles', filtering out the polyrhythmic soundscape of the city. Further, Bull notes that participants in his research rarely mention the spaces they pass through. Rather, they are often more attentive to their own mood and orientation, one which derives from their playlists. This he argues, neutralizes the public spaces of the city and makes all urban spaces potentially 'non-spaces'. Thus, he argues, iPod culture represents “an expression of personal creativity coupled with a denial of the physicality of the city" (2007; 9). 


\section{Tuning in? Urban soundscapes and social music listening}

Yet, if listeners do indeed create 'sound bubbles', there is potential for them to rupture. Such a rupture could come from the noises of the city penetrating into the listener's auditory experiences, or through other sensory distractions (a visual distraction, or physical contact, for example) that could immediately disengage the listener from their sonic isolation (Thulin, 2011). In re-conceptualizing Bull’s isolated audio bubbles, David Beer suggests that listening to music on the move is a 'tuning out' of the urban environment - "a process of distraction from the here-and-now” (2007; 858) - but that listeners are still exposed to urban soundscapes. Recognizing that sounds experienced as part of this 'tuning out' overlap and enmesh with urban soundscapes, Beer suggests, "precludes the need for drawing any imaginary barrier between the mobile listener and his/her surroundings” (2007; 859). Recognizing that such an imaginary barrier does not exist has important implications for the way in which we understand the use of these devices: as Beer suggests, it "creates opportunities for a more contextually integrated (less individually focused) analysis of the uses, users, and implications of the MP3 player” (2007; 859). In this respect, we consider Beer's intervention to be an important one.

However, we wish to take this line of argument further, to suggest that if mobile music devices can be used to 'tune out' the city - to distract from, transform and rewrite experiences of the city, but in ways that cannot ever be removed from the city - then they are also devices that allow listeners to attune themselves to the urban environment. As Coyne (2010; xvi) notes, if place is about the various ways in which people inhabit, interact, and socialize, then 'tuning' connects to "the lived experience of temporal and spatial adjustment”. However, Bull's account of mobile music consumption in cities is firmly couched in the 
negative aspects of the urban, as a 'defensive strategy' to manage the "perceived oppressive rhythms of daily life” (2007; 7); the "perceived oppressive and enveloping nature of the cosmopolitan urban crowd” (2007; 28); and the "repelling nature of urban life” (2007; 31). At best, his account emphasizes the banality and ‘drudgery’ of everyday urban life from which iPod users seek to escape. Yet, cities are also places of excitement and stimulation, of the familiar but also of the unfamiliar. Movement through the city involves a series of spaces and encounters that are negotiated through the senses and navigated through auditory and visual experiences - such as through music - in which city dwellers may seek out proximity and difference (Georgiou, 2013). Indeed, as Bull (2007) recognizes, in parallel to the privatizing tendency of these devices, there exists a compulsiveness towards proximity and contact in daily life.

Furthermore, mobile music listeners do not comprise a homogenous group. Stevenson (2013; 97) suggests that emotional responses to the city are "grounded in diverse patterns and biographies of use, experience and imagination, and informed by a range of social and cultural factors”, while Coyne (2010; 167) emphasizes that movement through the city is “opportunistic, drawing on cues, tags, labels, and devices to hand”. Thus amongst users of mobile music devices there will be multiple and diverse patterns of practice (Prior 2014) as they seek to shape their emotional encounters and non-encounters with urban spaces and places. In her study of MP3 player use in London, for example, Simun (2009) describes how while many users did use a digital music devices to ‘ignore’ their surroundings, some described becoming more receptive to their surroundings, for example through allowing them to relax and enjoy being in the city. Biggs (2008) suggests that many listeners choose music at least partially based on its relationship to their physical surroundings, with some reporting 
intense aesthetic experiences which leave them feeling more connected to their physical surroundings.

As such, we argue that 'tuning out' can only give us a partial account of mobile music use in the urban environment. We must also consider the ways in which it may be used a strategy for a 'tuning in' to the urban environment and enhancing the meaning and intensity of engagements with the city. In developing such an argument, we draw on two specific areas of academic enquiry. First, we consider recent writing on the 'sonic ecologies' of the city that emphasize 'city sounds' as part of the urban experience. Second, we consider second recent advances in technologies for situated music-exchanges and shared music interactions between mobile music listeners.

\section{Ecologies of urban sounds}

Recent work in human geography and urban studies has begun to recognize the importance of the urban soundscape to our experiences of the urban environment. For Barns $(2014 ; 6)$ the study of sound has helped "amplify more sensory, and situated, accounts of cities as places for our bodies”. Arkette (2004), for example, describes how particular locations have ‘sound markers' or ‘sonic profiles', which although may not be permanent features, reinforce spatial differences and identities. Aural space, she argues, is tactile and ephemeral, and highly fluid. Also recognizing the fluidity of the urban soundscape, Atkinson (2007) suggests that ambient urban soundscapes consist of a shifting aural terrain - of sonic ecologies consisting of a plethora of music, sounds and noises. This ecology is not a 
background to the urban experience but rather, Atkinson argues, is a resonant metropolitan fabric that implicates our movements and interactions and guides our experiences of the city.

In both recognizing the existence of an ecology of urban sounds to urban experience, and breaking down the imaginary barrier between the mobile music listener and the urban soundscape, we can begin to understand how music and urban sounds are not separate. Rather, the two soundscapes - external and internal - are synonymous to each other, overlapping and interrupting each other. Sound leakage exposes the music listener to 'urban overlays', and as they move around the city, they encounter other thresholds that bring abrupt changes in spectral envelopes of sounds and reverberations, and thus levels of leakage (Coyne, 2010). Further, Beer (2007) points to the fact that mobile music listeners may intentionally choose music that acts as an overlay on top of the existing soundscapes through which they move, suggesting that a mobile music device "extends or adds another frequency to the hum as it becomes part of the processes and infrastructures of the city” (2007; 859).

Therefore, while it might be desired by many listeners, mobile music cannot be viewed solely in terms of a 'tuning out' or 'drowning out' of the urban audioscape. In fact for some listeners, rather than being an unwelcome penetration of an isolated, individualized audioscape, the interference of the city's sounds and sights may actually enhance experiences of the city, with music overlaying and interacting with the external sounds from the urban environment as part of a technologically-mediated urban aural ecology. This represents a fluid interplay between sound, place and space. It is a 'tuning in' to the environment rather than a 'tuning out', with mobile music devices aiding in the re-creation of the city as a 
journey that takes place through a series of 'emotionally heightened spaces' (Anderson and Smith, 2001).

Location-aware and context-aware musical exchanges

Bull's account of iPod use suggests that the ‘solitude’ of the device blocks out not only the 'noise' of the city, but also the social environment, in a form of conscious social withdrawal. For Beer (2007), use of such devices constitutes as social distancing in which others can be ignored: people may choose to 'tune out' the physical as a means to mean avoid a particular social situation or interactions with people. Similarly, Tonkiss (2003; 304) describes iPod use as "social deafness". But here we would argue again that this account of 'tuning out' does not on its own capture the full range of uses of mobile music devices.

It is important to note at this juncture that both Bull's (2007) and Beer’s (2007) accounts are based around the use of the iPod, and could not predict the scale of the subsequent shift to mobile phones as the primary device for mobile music listening. Remarking on the impact of the iPhone on mobile music, the communicative functions of which facilitate sharing practices, Goggin (2011) argues that listening to music is often not the privatized, individual experience that many assume it to be. Rather, he suggests that there can be an intensely social and collaborative dimension to music, highlighted by the desire of listeners to share their preferences and music, and also swap with each other's recommendations and favorites. This draws a sharp contrast with Bull's notion of a “technologically mediated solitude” (2007; 5). For D’Arcangelo (2005), the fact that musical experiences are intrinsically social in nature means that the 'private barrier' of the mobile 
listener can be relatively easily overcome. He suggests that as soon as the desire to connect is presented, the mobile listener is likely to explore the possible connection.

The extent to which mobile music listening becomes a social experience is, of course, down to the individual and their methods of listening. At a basic level, this may involve the sharing of earphones or swapping of earphone jacks to engage with another's music something which has become known as 'jacking'. This is common amongst friends, but also occurs between strangers too: when sound leakage occurs from earphones, it allows users to effectively 'preview' what others are listening too, and where musical tastes are shared this can often result in a social interaction. However, as mobile phones have become the most significant devices for mobile music, they have provided the potential for a new level of connectivity between users. As Goggin (2011) suggests, unfolding with the intersection of cell phones and music have been a range of ways that phone and music companies have sought to cater to, and capitalize on, this new mobile music sharing.

Thus these devices, we would suggest, provide unique opportunities for listeners to 'tune in' to those around them, rather than tuning out. Significant in this regard have been developments around the shared playlist on services such as Spotify, which allow users to share their musical identities online. This has added more social elements to listening experiences, and extended the individual listening experience into networks of shared music and information that look to connect listeners with similar taste (D’Arcangelo, 2005). Many programmes now capture spatial data alongside consumption data. Shazam, for example, allows users to explore the most commonly listened to music within different cities and districts of cities, allowing users to access a 'local' playlist. 
However, most significantly in terms of debates around urban soundscapes are new developments in urban computing and GPS technologies that track the position and movement of the mobilized individual. In the context of mobile music, these technologies have allowed for the creation of programs for 'location-aware' or 'context-aware' interactive musical exchanges that allow nearby users to access each other's playlists. While this is not a physical interaction (although in theory it could lead to one), it allows users to find someone with similar musical taste in a shared virtual interaction. Using the rich sensing capabilities of mobile phones, these context-aware music recommender systems are able to take into consideration contextual conditions, such as the time and the user's mood or location, and the dynamics of urban space related to different times of day or different seasons, that may influence the user’s preferences at a particular moment (Braunhofer et al., 2013; Åman et al., 2015).

One can point to numerous technological innovations and prototypes that point to the future of location and context-aware music services and applications. Bassoli et al. (2007), for example, describe the development of a music-exchange application Undersound based on explicitly foregrounding the diverse and often contradictory experiential qualities of commuting on the London underground. Commuters are able to upload tracks at particular upload points where others can then download the tracks. Similarly, Åman and Liikkanen (2013) describe the development of the SoundAbout application, which enables users to see what music has been listened to in particular locations in the city at a particular time, as well as 'attaching' music to particular locations. Such location based mobile information services, 
then, 'augment' the city with a digital information layer - situated data about soundtracks in place - which people can add to and draw from:

Imagine that you have a spray can full of music, millions of songs you can use to paint the city with music, take over the city by dropping music in places meaningful to you, all over the town and share those location, time and music combinations with your friends, or with anybody to explore, enjoy and modify. (Åman and Liikkanen, 2013; 542)

Some applications have more explicit social elements. Seeburger et al. (2012) describe the development of a prototype mobile application called Capital Music which enables real-time sharing of song choices with collocated urban dwellers. The application incorporates Location-Based Networking (LSBN), which enables the exchange of messages between users to "facilitate interaction between unknown urban dwellers in public places" (2012; 8). Their findings from the testing of the prototype suggest that music is perceived as an ideal ‘icebreaker’ for mediated social interactions.

This type of exchange network offers new kinds of urban audio experiences that are situated in a virtual layer of digital information, but one that is embedded both within the physical structure and social environment of the city through locational and emotional 'tags'. Further, they result in exchanges of music that are not just informational but which may also be playful, emotional, and ambiguous. Galloway (2004), for example, describes a musical prototype called Teijp which, inspired by situationism, graffiti and street art explores 
possibilities for overlaying personal traces in such a way as to encourage playful ways of personalizing territory.

The context and location-specific music recommendations that result from such technologies, we argue, are examples of how mobile music listeners are tuning ‘in’ rather than 'out' to the social and collective experiences of the city through music, forming individual and collective mediated, yet engaged, relationships with their urban environment. As these services become more interactive, users are able to move beyond individual soundtracks to connect with moods, emotions, and movements of others through musical recommendations. For Coyne (2010) this capability mirrors aspects of everyday sociability and spatiality, as people enter, meet and pass one another in different physical spaces. Challenging Bull’s notions of media ‘isolation', the others with which users engaged are not 'absent', but are those who are co-located in, move through, and share experiences of, the same urban environments. Rather than, as Bull suggests, urban spaces becoming bereft of meaning through mobile music listening, these exchanges constitute sites as locations for individual and collective meaning-making through music.

\section{Concluding discussion}

Our contention in this paper has been that, if mobile music devices can be used to 'tune out' the city, they are also devices that allow listeners to tune in to the urban environment. As Prior $(2014 ; 36)$ notes, these devices allow listeners to "withdraw them from the urban, for sure, but also to enhance their social spheres, to reflect on their predicaments, to resist and prick their bubbles”. The neglect of the social and physical contexts of music 
listening in previous accounts of mobile music has led to accounts that emphasize 'aestheticized' emotions coming from the structure of the music itself (see Juslin and Laukka, 2004), at the expense of accounts that recognize that uses and experiences of music are often tied directly to experiences, sounds and emotions in the everyday social and physical environment of the listener.

As the work of Michael Bull has been crucial in highlighting, mobile music devices, in becoming intimately incorporated into everyday routine bodily practices, are allowing listeners to shape their emotional encounters (or, more specifically, non-encounters) with urban spaces and places. But the concept of 'tuning out', we argue, only presents a partial picture. In many cases, such as for example the use of location-aware music applications as described in this paper, these devices can intensify encounters with the city, acting as catalysts that expand and enhance situated real world experience. To be clear, the concept of 'tuning in' developed in this paper does not sit in direct opposition or tension with, 'tuning out'. Rather the two concepts represent heuristic devices that seek to understand and describe what are, in reality, a highly complex set of everyday ‘tactics’ (de Certeau, 1984) for engagements or non-engagements with the urban. The few empirical studies of mobile music listening, notably Prior (2007) and Simun (2009), as well as a closer interrogation of the empirical material presented by Bull (2007), point to the ways in which mobile music devices become “dramatically and skillfully folded into multiple patterns of practice” (Prior, 2014; 36).

It is to these complexities of practice and experience that we as urban researchers need to attend. As Bull notes, the fact that media technologies simultaneously isolate and 
connect is "the dilemma at the heart of our understanding of how we increasingly inhabit the public spaces of urban culture” (2007; 9). What are required then are more nuanced understandings of the intrinsic and complex relationships between mobile music, listeners, and the urban environment, and the resulting sonic, emotional and social geographies of the city. Developing a fuller understanding of the role of sound in urban experience can help us to get to grips with the more "ephemeral and shifting elements of urbanism that often slip through our fingers when we try to give concrete assessment of its character” (Atkinson, 2007; 1905). The arguments developed in this paper regarding ‘tuning in’ are an important step forward in this regard. Yet, this represents just one part of the wider theoretical and empirical project of assessing the ways in which the pervasiveness of mobile devices and wireless technologies are recalibrating the experience of urban spatiality through the creation of ubiquitous body-network relations (Fuller and Harley, 2011). Such a project is necessary so as not to present through our research "a version of technology bereft of everyday dissonances, disagreements and contingencies of practice and an urban subject who is emptied out of agency and the complexities of being engaged with technology" (Prior, 2014; 37). Urban studies scholars should be at the forefront of such a project, with the necessity for engagement is given further impetus by the rapidity of technological development and change.

\section{References}

Åman, P. and L.A. Liikkanen (2013) Painting the city with music: context aware mobile services for urban environment. Continuum: Journal of Media \& Cultural Studies, 27.4, 542-557. 
Åman, P., L.A. Liikkanen and A. Hinkka (2015) Enriching user experiences with locationsensitive music services. Journal of Location Based Services 9.3, 167-186.

Anderson, K. and S.J. Smith (2001) Editorial: emotional geographies. Transactions of the Institute of British Geographers 26.1, 7-10.

Arkette, S. (2004) Sound like city. Theory, Culture \& Society 21.1, 159-168.

Atkinson, R. (2007) Ecology of sound: the sonic order of urban space. Urban Studies 44.10, 1905-1917.

Barns, S. (2014) Sounds different: listening to the proliferating spaces of technological modernity in the city. Space and Culture 17.1, 4-15.

Bassoli, A., J. Brewer, P. Dourish, K. Martin and S. Mainwaring (2007) Underground aesthetics: rethinking urban computing. Pervasive Computing July-September 2007.

Belgiojosa, R. (2014) Constructing Urban Space with Sounds and Music. Ashgate, Farnham.

Biggs, B. (2008) Like it was a movie: cinematic listening as public art. Working paper \#36, Fall, 2008 Princeton University Centre for Arts and Cultural Policy Studies.

Beer, D. (2007) Tune out: music, soundscapes and the urban mise-en-scene. Information, Communication \& Society 10.6, 846-866.

Beer, D. (2008) The iconic interface and the veneer of simplicity. Information, Communication \& Society 11.1, 71-88.

Beer, D. (2012) The comfort of mobile media: uncovering personal attachments with everyday devices. Convergence: The International Journal of Research into New Media Technologies 18.4, 361-367. 
Braunhofer, M., M. Kaminskas and F. Ricci (2013) Location-aware music recommendation. International Journal of Multimedia Information Retrieval 2, 31-44.

Bull, M. (2005) No dead air! The iPod and the culture of mobile listening. Leisure Studies 24.4, 343-355.

Bull, M. (2006) Investigating the culture of mobile listening: from Walkman to iPod. In K. O’Hara and B. Brown (eds.) Consuming Music Together: Social and Collaborative aspects of Music Consumption Technologies, Springer, London.

Bull, M. (2007) Sound Moves: iPod Culture and Urban Experience, Routledge, London and New York.

Bull, M. (2013) iPod use: an urban aesthetics of sonic ubiquity. Continuum: Journal of Media \& Cultural Studies 27.4, 495-504.

Coyne, R. (2010) The Tuning of Place: Sociable Spaces and Pervasive Digital Media, MIT Press, Cambridge MA and London.

D’Arcangelo, G. (2005) The new cosmopolites: activating the role of mobile music listeners. Paper presented at the ESI Design/New York University 2nd International Mobile Music Workshop, Vancouver, BC, Canada May 25, 2005.

De Certeau, M. (1984) The Practice of Everyday Life, University of California, Berkeley.

Fuller, G. and R. Harley (2011) The protocological sound: reconceptualizing radio and architecture in the wireless city. In M. Foth, L. Forlano, C. Satchell and M. Gibbs (eds.) From Social Butterfly to Engaged Citizen: Urban Informatics, Social Media, Ubiquitous Computing, and Mobile Technology to Support Citizen Engagement, MIT Press, Cambridge MA and London. 
Gallagher, M. (2013) Sonic geographies: exploring phonographic methods. Progress in Human Geography 38.2, 267-284.

Galloway, A. (2004) Imitations of everyday life: ubiquitous computing and the city. Cultural Studies 18.2/3, 384-408.

Goggin, G. (2011) Global Mobile Media, Routledge, London and New York.

Juslin, P.N. and P. Laukka (2004) Expression, perception, and induction of musical emotions: a review and a questionnaire study of everyday listening. Journal of New Music Research 33.3, 217-238.

Prior, N. (2014) The plural iPod: a study of technology in action. Poetics 42, 22-39.

Simun, M. (2009) My music, my world: using the MP3 player to shape experience in London. New Media \& Society 11.6, 921-941.

Skånland, M.S. (2011) Use of MP3 players as a coping resource. Music and Arts in Action $3.2,15-33$.

Stevenson, D. (2013) The City, Polity Press, Cambridge.

Thibaud, J. (2003) The Sonic Composition of the City. In M. Bull and L. Back (eds.) The Auditory Culture Reader, Breg Publishers, Amsterdam, 329-341.

Thulin, S. (2011) 'There to hear': reimagining mobile music and the soundscape in Montreal. Paper presented at the $1^{\text {st }}$ Global Conference on Urban Popcultures, $8^{\text {th }}-10^{\text {th }}$ March 2011, Prague, Czech Republic

Tonkiss, F. (2003) Aural postcards: sound, memory and the city. In M. Bull and L. Back (eds.) In M. Bull and L. Back (eds.) The Auditory Culture Reader, Breg Publishers, Amsterdam. 
Wissman, T. (2014) Geographies of Urban Sound. Ashgate, Farnham. 